\title{
LA MUJER CASADA Y EL PAPEL DE LA EDUCACIÓN PARA SU CRECIMIENTO PERSONAL: ANÁLISIS DE LAS PUBLICACIONES DE LA ESCUELA MODERNA (1901 - 1917)
}

\author{
Estefanía Fernández-Antón*
}

\section{RESUMEN}

Desde este documento buscamos identificar la realidad de la mujer casada del 1901 al 1917 a través de las publicaciones de la Escuela Moderna e identificar el valor que tenía la educación para su desarrollo personal. Para todo ello, nos basamos en la revisión del Boletín de la Escuela Moderna desde el año 1901 hasta el 1903 y en otras de sus creaciones (conferencias, cuentos, folletos, obras dramáticas, etc.) que comprenden hasta el 1917. Los resultados obtenidos indican que las publicaciones racionalistas apoyaban que la mujer se uniera en matrimonio por amor y que éste fuera un vínculo que no generase su sometimiento.

Palabras clave: Escuela Moderna, educación femenina, matrimonio.

* Universidad Internacional de La Rioja (UNIR), La Rioja, Espanha. 


\title{
A MULHER CASADA E O PAPEL DA EDUCAÇÃO PARA O DESENVOLVIMENTO PESSOAL: ANÁLISE DAS PUBLICAÇÕES DA ESCOLA MODERNA (1901-1917)
}

\section{RESUMO}

Desde este documento procuramos identificar a realidade da mulher casada desde 1901 a 1917 nas publicações da Escola Moderna e identificar o valor que a educação tinha para o seu desenvolvimento pessoal. Para isso, baseamos-nos na revisão do Boletim da Escola Moderna desde o ano 1901 até 1903 e em outras publicações (conferências, contos, folhetins, obras dramáticas, etc.) que vão até 1917. Os resultados obtidos indicam-nos que as publicações racionalistas defendiam que a mulher contraísse casamento por amor e que este fosse um vínculo que não gerasse submissão.

Palavras-chave: Escola Moderna, educação feminina, casamento.

\section{THE MARRIED WOMEN AND THE ROLE OF EDUCATION FOR THE EMPOWERMENT: ANALYSIS OF PUBLICATIONS OF THE MODERN SCHOOL (1901-1917)}

\begin{abstract}
From this document we identify the reality of the woman married from 1901 to 1917 in the publications of the Modern School and to identify the value that education has for her personal development. For all this, we rely on the revision of the Bulletin of the Modern School from 1901 to 1903. The analysis also includes other of her publications (conferences, stories, brochures, dramatic books, etc.) that comprise until 1917. The results say that the rationalist publications supported the woman marry for love. They also argue that it had to be a union without submission.
\end{abstract}

Keywords: Modern School, female education, marriage.

\section{LA FEMME MARIEEET LE RÔLE DE L'ÉDUCATION POUR L' ÉMANCIPATION: ANALYSE DES PUBLICATIONS DE L'ÉCOLE MODERNE (1901-1917)}

\section{RESUME}

Le présent document identifie la réalité des femmes mariées de 1901 à 1917 dans publications de l'École Moderne. Nous cherchons également à identifier le rôle de l'éducation dans l'émancipation de ces femmes. Pour cela, nous nous appuyons sur la lecture du Bulletin de l'École Moderne, entre 1901 et 1903 ainsi que leurs autres créations (conférences, contes, livrets, romans, etc.), jusque 1917. Les résultats obtenus nous indiquent que les publications rationalistes soutenaient alors la femme à se marier par amour et que ce devait être un lien ne générant pas une soumission.

Mots-clés: l'École Moderne, éducation des femmes, mariage. 


\section{INTRODUCCIÓN}

En las primeras décadas del siglo XX, la mujer tenía la misión primordial de cuidar y de mantener a salvo a la familia y al hogar. Para ello, desempeñaba los roles de esposa y de madre dentro del espacio doméstico, para así no poner en peligro a la institución familiar. Por otro lado, el Código Civil del momento determinaba que el hombre era el jefe indiscutible de la familia y que su función era la de proteger a la mujer a cambio de su obediencia infinita (CIEZA, 1986).

El contexto histórico que acompañaba a la mujer recién presentada es la Restauración borbónica ${ }^{1}$ (NASH, 1983). De acuerdo con Nash (1993), dentro de esta etapa histórica, se mantenía la idea de la mujer como ángel del hogar; no obstante, el discurso del género fue introduciendo otras posturas que presentaba a una mujer moderna, instruida y profesional; aunque estas novedades seguían asociando a la mujer con la maternidad.

Dentro del ámbito privado, se destacaba el papel de madre y el de esposa. Considerándose a ambos como los objetivos a los que debería aspirar toda mujer. Aunque cerca del 1917, los discursos feministas planteaban otras opciones como algunas de las ya indicadas: la instrucción, la participación en la esfera pública más allá de sus dos papeles impuestos, el amor al prójimo sin la necesidad de ser éste encaminado hacia la formación de una familia, etc. Este cambio para la mujer y la crisis socioeconómica de la restauración, que se suele situar próxima al 1917 (SERRALLONGA I URQUIDI, 1991) han determinado que la fecha de cierre del análisis documental sea la recién indicada. La fecha de inicio del análisis coincide con la primera publicación de la Escuela Moderna y con la apertura de dicha institución.

Antes de que la Escuela Moderna abriera sus puertas, la Ley de Moyano de 1857 planteó algunas medidas a favor del avance de la educación femenina, las

\footnotetext{
${ }^{1}$ La Restauración borbónica fue un sistema político español que tuvo sus inicios en el año 1874, justo después del Sexenio Democrático (1868-1874). El sexenio indicado fue interrumpido por un golpe de estado encabezado por el General Arsenio Martínez Campos. Después de este suceso se implementó la vuelta de la Monarquía Española y de la dinastía borbónica hasta la II República en el 1931 (MUÑOZ, 2018).
} 
cuales tuvieron influencia hasta las primeras décadas del siglo XX. La legislación y su inclinación por la creación de escuelas de niñas reconocía que las mujeres tenían derecho a recibir una instrucción primaria y una formación pedagógica respectivamente. Sin embargo, estas medidas no fueron suficientes para igualar la instrucción femenina a la masculina y dieron como resultado asignaturas que preparaban al hombre para el mundo laboral y asignaturas que delegaban a la mujer a cumplir con su misión de esposa y de madre (SCANLON, 1986).

Para acortar la distancia entre la instrucción femenina y la masculina, los institucionistas influyeron en la política pedagógica de los ministerios liberales y participaron en organismos dependientes del Ministerio de Instrucción Pública, tales como el Consejo de Instrucción Pública, la Dirección General de Instrucción Primaria y la Junta de Ampliación de Estudios y, asimismo, crearon sus propios organismos como el Instituto Escuela y la Residencia de Señoritas (ONTAÑóN, 2003; SCANLON, 1986). Aparte de los institucionistas, la preocupación por la educación, como base para equiparar al hombre y a la mujer, recae también en movimientos como el catolicismo más liberal, posiciones feministas minoritarias de hombres y de mujeres que tuvieron relación con el institucionismo y socialismo (Pardo Bazán, Concepción Arenal, Berta Wilhelmi, Torres Campos, Labra, etc.) (BALLARÍN, 1989).

En la lista de proyectos que buscan la igualdad de las mujeres también encontramos las acciones de las escuelas racionalistas, como la Escuela Moderna de Ferrer i Guàrdia (PALOMERO, 1998) en la que nos detenemos en este trabajo para examinar sus publicaciones, ya que buscamos alcanzar los siguientes objetivos: conocer la realidad de la mujer casada de principios de siglo XX, desde la perspectiva de las publicaciones racionalistas de la editorial de la Escuela Moderna de Barcelona, e identificar el valor de la educación para el crecimiento personal de la mujer casada. 


\section{LA ESCUELA MODERNA DE FERRER I GUÀRDIA Y SUS PUBLICACIONES}

La Escuela Moderna de Ferrer i Guàrdia nació el 8 de septiembre de 1901 en Barcelona y cerró sus puertas en 1906. Su ideario era racionalista y laico, su identidad era un ejemplo rotundo de la conexión de la enseñanza con el pensamiento anarquista y su marco pedagógico planteaba la renovación de la Pedagogía dentro de la corriente de carácter obrero (CAPPELLETTI, 2010; VIÑES, 1983).

Se centraba en la enseñanza de las Ciencias Naturales, las Matemáticas, la Lengua y la Literatura, etc., con el empeño de no suprimir el vínculo entre la persona (fuera cual fuera su origen socioeconómico) y el conocimiento. Por este motivo, en la escuela, se enseñaba sobre animales unicelulares y pluricelulares, se estudiaba la célula y su composición, la fisiología, la anatomía y la reproducción. Se hablaba sobre los números y las ecuaciones. Y no se olvidaba de las obras clásicas contemporáneas como las de Pérez Galdós; Alfredo Calderón; Picón, entre otros contenidos (ESCUELA MODERNA, 1901).

También se tenía interés por el ejercicio manual, que podía ser el dibujo libre en la pizarra o el dibujo orientado, para la realización de piezas cúbicas de construcción. La realización de tejidos, el plegado y el recorte de papel eran otras de las actividades educativas que se planteaban para el desarrollo de las habilidades manuales (ESCUELA MODERNA, 1901a).

El método pedagógico de la Escuela Moderna se basaba en la eliminación de exámenes, premios y castigos; atención a la higiene; introducción del juego para aprender en el aula; excursiones instructivas, en la solidaridad entre compañeros y la coeducación de sexos. Los materiales de aprendizaje eran libros didácticos publicados por la editorial de la Escuela Moderna, estos documentos trataban sobre temas de Biología, de Física, de Sociología, etc. (DELGADO, 1982). Otros materiales eran láminas de Fisiología y de Botánica en las paredes, mapas, el Boletín de la Escuela Moderna y otras publicaciones de su editorial (Publicaciones de la Escuela Moderna) (MURO, 2009; LÁZARO, 2016). 
El Boletín de la Escuela Moderna comenzó el 30 de octubre de 1901 con una periodicidad mensual. En sus páginas, que se centran en la educación racional y científica, entre otros asuntos, se pueden leer artículos escritos por pedagogos, pedagogas, profesionales de la medicina, etc., de España y de Francia principalmente (VELÁZQUEZ, 2008). También hay artículos que analizan la sociedad del momento, reflejan los contenidos trabajados dentro de la escuela y comunican información a las familias como las notas académicas o las impuntualidades de los estudiantes.

Los asuntos que nos interesan de todos los que se publicaron son aquellos que analizan la situación de la mujer casada y la forma de mejorar su realidad, debido a que, a principios del siglo XX, el matrimonio posicionaba a la mujer de manera desigual respecto al hombre en el contexto español (CIEZA, 1986).

El Boletín de la Escuela Moderna también fue una de las primeras publicaciones, en el cual maestras españolas tuvieron la oportunidad de escribir sobre didáctica y sociedad (Teresa Mañé, Belén Sarraga, Amalia Domingo Soler, etc.), así como educadoras de otros países: Alejandra Myrial, Ellen Key, Clemencia Jacquinet, etc. (MARÍN, 2009). Jacquinet fue la primera directora de la escuela y la que parece que fue la primera mujer que participó en el boletín mediante un artículo denominado Observaciones generales, sobre el primer mes de clase. Éste data de 1901, año de inicio del boletín, y resume los primeros días de trabajo de la escuela. Además, aporta algunos consejos que deben tener en cuenta los docentes (JACQUINET, 1901).

La publicación comenzó el 30 de octubre de 1901 y su fecha de cierre fue el 1 de julio de 1909. Dentro de este período, el boletín tiene dos etapas, la primera abarca del 30 de octubre de 1901 hasta el 31 de mayo de 1906. El segundo periodo comienza en junio de 1906 y coincide con el momento de encarcelamiento de Francisco Ferrer, debido a que se le consideró cómplice por el delito de regicidio frustrado que fue iniciado por Mateo Morral (VELÁZQUEZ, 2008). De estas etapas, nuestro estudio se centra en los boletines disponibles de la escuela, en la Fundación Ferrer i Guàrdia, lo que supone un análisis de las publicaciones del 
año 1901 al 1903, así como de algunos números sueltos de la segunda etapa del boletín, con la publicación de la revista L École Renovée y la Extensión internacional de l'Ecole Moderne de Barcelona con sede en Bruselas, y en otros tipos de publicaciones: conferencias, cuentos, folletos y obras dramáticas.

En lo que refiere a las otras publicaciones de la Escuela Moderna, desde algunas de sus obras (BENOT, 1916; SAUERWEIN, 1925, etc.), se puede ver el catálogo general al final. La clasificación de dicho contenido es la que hemos seguido y suele estar dividida en cantos de la Escuela Moderna, conferencias, cuentos, folletos, libros de lectura, obras generales, obras dramáticas y relatos de hombres eminentes.

Los temas de las publicaciones son muy variados; no obstante, podemos resumirlos en análisis de la sociedad y en la enseñanza de contenidos académicos concretos (aritmética, francés, la gramática castellana, etc.). Los del primer tipo analizaban la sociedad del momento o de tiempos pasados desde diferentes ciencias: Antropología, Historia, Psicología, etc., y también se consideraban parte del contenido educativo de la escuela.

\section{ESTUDIOS PREVIOS}

Los estudios sobre Ferrer i Guàrdia son muy abundantes y así lo aseguraba Delgado nada más iniciarse los años 80: "quien intenta profundizar en la historia de Ferrer y de su Escuela Moderna queda pronto desanimado ante el cúmulo de publicaciones existentes sobre el tema" (DELGADO, 1982, p. 7).

Después de principios de los 80, el número de estudios sobre el tema ha seguido creciendo; no obstante, consideramos que todavía hay temas que se pueden examinar sobre esta escuela y sus publicaciones, en lo que se refiere a términos muy específicos como el que aquí proponemos, ya que hasta ahora sobre todo abundan trabajos muy amplios, que tocan la escenografía de la escuela y el procesamiento de Ferrer, así como la identidad y la vida del pedagogo. 
En relación con la escenografía de la escuela y el procesamiento penal de Ferrer nos encontramos con algunos estudios destacados: Archer (2010); Aubert y Siles (2009); Bergasa (1990); García-Yeste, Redondo-Sama, Padrós y Melgar (2016); Marín (2009); etc. Estos trabajos aportan un relato detallado de la enmarañada escenografía en la que se gestó la Escuela Moderna y el procesamiento de Ferrer i Guàrdia.

$\mathrm{Y}$ en lo que se refiera a la identidad y vida del pedagogo encontramos otros trabajos bastante conocidos: Avilés (2006); Delgado (1982); Muro (2009); Palomero (1998); Solà (2010, 2011); Torrebadella (2016); etc.

En relación con los estudios previos más próximos a nuestros objetivos y, por tanto, sobre las publicaciones de la Escuela Moderna, queremos destacar la tesis doctoral de Velázquez (2008) que pretende analizar los principios educativos de la institución; los recursos personales e institucionales con los que contaba; cómo se fundamentó la crítica al orden social, entre otras pretensiones. Para este fin, se revisan las publicaciones de la Escuela Moderna. Además, dentro del documento, hay una aproximación hacia el tema del matrimonio, pero sin centrarse exclusivamente en el mismo.

Del mismo autor, Velázquez, y en compañía de Viñao (VELÁZQUEZ; VIÑAO, 2010), encontramos otro trabajo que pretende analizar el tipo de publicaciones de la Escuela Moderna desde la edición de Ferrer i Guàrdia hasta la de su último sucesor Maucci (desde 1925 a 1936). Así pues, sus objetivos se distancian de los nuestros; no obstante, hemos considerado oportuno añadir este estudio al tener relación con parte de las publicaciones que aquí examinamos.

Quisiéramos acabar esta revisión teórica con otro trabajo que se acerca más a nuestras pretensiones, que es el de Nadal-Masegosa (2018). Éste muestra el trabajo de feministas francesas y españolas dentro del Boletín de la Escuela Moderna. No obstante, en nuestro estudio, el tipo de publicaciones analizadas es más diverso y orientamos el análisis hacia la mujer casada.

Por último, señalamos que fuera del contexto español encontramos 
trabajos que abordan el discurso de los anarquistas chilenos y argentinos, del siglo XIX y hasta mediados del siglo XX, en relación con las prácticas sexuales y amorosas (FERNÁNDEZ, 2007; GODOY, 2011).

\section{CONSIDERACIONES METODOLÓGICAS}

El análisis de fuentes documentales primarias es el procedimiento metodológico que seguimos en este estudio. Hemos dispuesto de algunas de ellas en la biblioteca de la Fundación Ferrer i Guàrdia, situada en el Carrer d'Avinyó de Barcelona. En éste y otros espacios se pueden encontrar otras publicaciones de la institución que examinamos. Ahora bien, hemos seleccionado aquellas que podían encajar con nuestros objetivos. En este sentido, hemos analizado algunas de las publicaciones editadas por la Escuela Moderna relacionadas con la historia, la educación, la sociedad, la familia y la mujer. Los documentos no seleccionados tratan sobre: geografía, gramática, aritmética, escritura, la composición del botiquín escolar, etc.

Las fechas de las publicaciones analizadas son del 1901 a 1917. En este periodo de tiempo la editorial de la Escuela Moderna estuvo bajo la dirección de Ferrer (1901-1909) y de Lorenzo Portet (1912-1920) (VELÁZQUEZ; VIÑAO, 2010).

De la etapa de dirección de Ferrer i Guàrdia hemos analizado los siguientes boletines escolares (ver tabla 1). 
Tabla 1 - Fuentes primarias: Boletines de la Escuela Moderna analizados².

\begin{tabular}{|c|c|}
\hline PERIODICIDAD & BOLETINES \\
\hline $\begin{array}{c}\text { Octubre de } 1901- \\
\text { junio de } 1902\end{array}$ & $\begin{array}{l}\text { 1. Boletín de la Escuela Moderna. Barcelona, año I, núm. 1, } 30 \\
\text { de octubre de } 1901 . \\
\text { 2. Boletín de la Escuela Moderna. Barcelona, año I, núm. 2, } 30 \\
\text { de noviembre de } 1901 . \\
\text { 3. Boletín de la Escuela Moderna. Barcelona, año I, núm. 3, } 31 \\
\text { de diciembre de } 1901 . \\
\text { 4. Boletín de la Escuela Moderna. Miscelánea Infantil, Ciencia } \\
\text { y Literatura. Ediciones de la Escuela Moderna. 1901. Núm. 61 y 63. } \\
\text { 5. Boletín de la Escuela Moderna. Barcelona, año I, núm. 4, } 31 \\
\text { de enero de 1902. } \\
\text { 6. Boletín de la Escuela Moderna. Barcelona, año I, núm. 5, } 31 \\
\text { de marzo de } 1902 \text {. } \\
\text { 7. Boletín de la Escuela Moderna. Barcelona, año I, núm. 6, } 30 \\
\text { de abril de } 1902 . \\
\text { 8. Boletín de la Escuela Moderna. Barcelona, año I, núm. 7, } 31 \\
\text { de mayo de } 1902 \text {. } \\
\text { 9. Boletín de la Escuela Moderna. Barcelona, año I, núm. 8, } 30 \\
\text { de junio de } 1902 .\end{array}$ \\
\hline $\begin{array}{l}\text { Octubre de } 1902- \\
\text { junio de } 1903\end{array}$ & 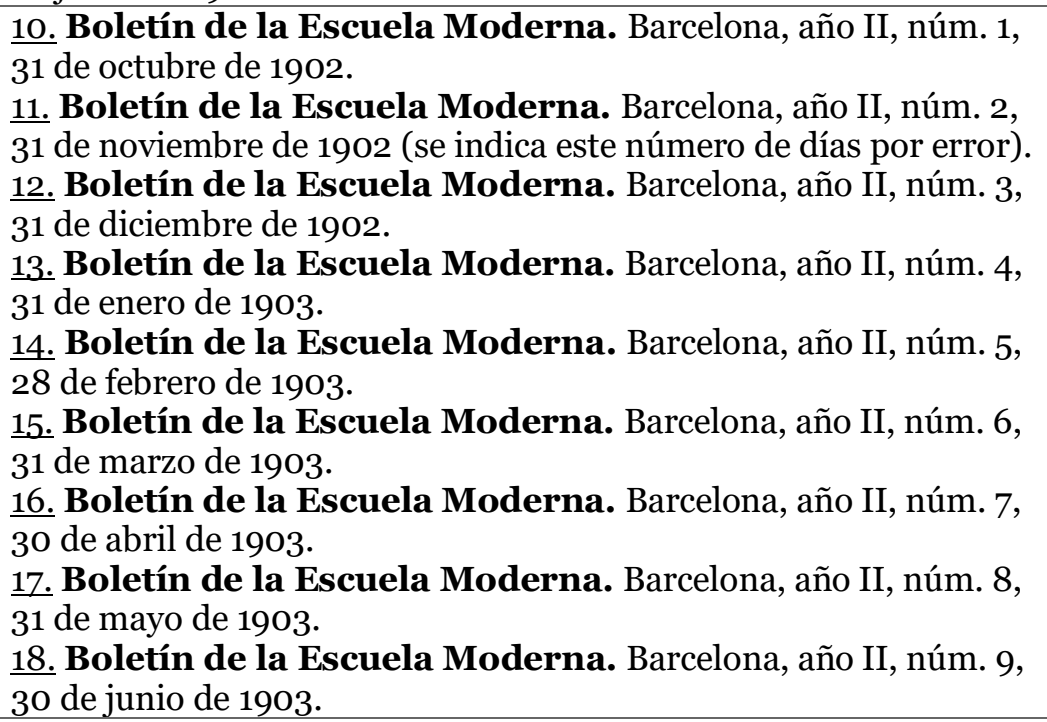 \\
\hline
\end{tabular}

Fuente: elaboración propia a partir de Velázquez (2008).

Los 18 boletines anteriores han sido examinados para aproximarnos a nuestros objetivos: conocer la situación de la mujer casada e identificar la importancia de la educación para potenciar su valor. Para ello, hemos revisado 139 artículos aproximadamente, ya que el número exacto es difícil de plantear,

\footnotetext{
2 Nadal-Masegosa (2018) asegura que el análisis de estos boletines es una muestra representativa
} para los primeros años de la Escuela Moderna. 
porque en alguna ocasión no está claro donde comienzan y acaban algunos de los trabajos. De estos artículos hemos recogido aquellos que se centran en la mujer y la educación.

De la segunda etapa del Boletín, denominado como L 'École Renovée, hemos recogido dos trabajos: Elslander (1908a) y Ferrer i Guàrdia (1908).

Aparte del Boletín de la Escuela Moderna, otros documentos analizados son obras variadas (FERRER I GUÀRDIA, 1912; LORENZO, 1909; LLURIA 1905, 1906; NAQUET, 1909; URALES, 1906), una obra dramática (CHARDÓN, 1906), un folleto compuesto por dos obras (CHAUGHI, 1902; ROBIN, 1908), un cuento (GRAVE, 1908) y una conferencia (ANTICH, 1915). Hemos realizado esta clasificación fijándonos en los catálogos generales que incluían dos obras de la Escuela Moderna: Benot (1916) y Sauerwein (1925). Además, otros documentos les hemos encontrado en la investigación previa de Velázquez (2008)3.

El conjunto de teóricos que determinan la historiografía de este trabajo tienen perfiles muy variados: participantes femeninas como Juana Rino y Alicia Maur; activistas del movimiento anarquistas francés: Jean Grave y René Chaughi; el pedagogo y anarquista francés Paul Robin; el antropólogo francés Charles Letourneau; el anarquista español Anselmo Lorenzo; políticos españoles como Francisco Pi y Maragall; escritores y maestros como Juan Montseny Carret, cuyo seudónimo era Federico Urales; el fundador y pedagogo de la Escuela Moderna Ferrer i Guàrdia, etc.

3 1- ESCUELA MOdERnA. La Mujer (Mujer Privada-Mujer Pública). Barcelona, Casa Editorial Publicaciones de La Escuela Moderna, s. f. El folleto está formado por dos artículos: CHAUGHI, René. La mujer esclava. Boletín de la Escuela Moderna, 3, 27-29, Año II, 1902. ROBIN, Paul. (1908). La mujer pública. 2- BESSÈDE, G.M. Lo que todos deberían saber

(La iniciación sexual). Barcelona, Casa Editorial Publicaciones de La Escuela Moderna, 1917. 


\section{LA MUJER CASADA EN LAS PUBLICACIONES DE LA ESCUELA MODERNA}

A principios del siglo XX, el matrimonio establecía un vínculo de carácter conyugal entre un hombre y una mujer. Dentro de esta unión, la mujer era considerada como la responsable del cuidado de la familia y del hogar. Además, sus funciones quedaban delegadas al entorno doméstico normalmente.

Para mejorar la visibilidad y la realidad de la mujer, las escuelas racionalistas, como por ejemplo la Escuela Moderna de Ferrer i Guàrdia, defendían entre sus postulados la coeducación de sexos, con el objetivo de que la mujer superase la triple esclavitud a la que estaba sometida: esclavitud de ignorancia, esclavitud al trabajo y esclavitud por ser mujer (PALOMERO, 1998). Se consideraba que esta realidad solo podría ser superada si la sociedad tenía en consideración a la mujer y su lugar en el mundo. Los racionalistas lo tenían muy claro, su lugar no era estar recluida en el hogar, su lugar era buscar la igualdad con el hombre y la búsqueda de una vida mejor, alejada de la ignorancia a través del contacto con la cultura (ESCUELA MODERNA, 1901b).

\section{PRESIÓN Y SOMETIMIENTO}

En uno de los artículos del Boletín de la Escuela Moderna, se planteaba que un matrimonio que no completara a la mujer podía dar lugar a una vida vacía y desprovista de sentido. Se realizaba esta afirmación, porque casarse era uno de los objetivos principales que tenían que cumplir las mujeres del momento (CIEZA, 1986; NASH, 1983, 1993) y, si éste resultaba no ser positivo, al no atribuirles muchas otras metas principales, la vida podría resultar insoportable. Asimismo, se establecían otras posibles consecuencias en el cual podría desembocar el matrimonio, como la transformación negativa del cuerpo; para ello, se utilizaban adjetivos, como es el de amorfo. De esta manera, se remarcaba que el matrimonio podía destruir la composición física de la mujer, idea que sin 
duda genera una esfera de dramatismo vinculado a la idea de mujer casada, porque se establecía de forma simbólica que uno de sus fines podía ser el de la perdida de las cualidades físicas que forman a la persona: "que se convierten luego en seres desgraciadamente impersonales y amorfos cuando el matrimonio no les completa" (SÉE, 1902, p. 99).

Asimismo, se veía al matrimonio como un acto de sometimiento al hombre, ya que, en el momento que una mujer se casaba, pasaba a ser considerada una de sus propiedades y se la suprimían sus derechos naturales:

El matrimonio, tal como existe, es degradante para la mujer, que se sujeta a la autoridad del marido, se halla dificultada en sus actos, privada de los derechos civiles y, no obstante, está investida de la alta misión de maestra y educadora de las generaciones (R, 1903, p. 83).

Ideas similares las identifica Velázquez (2008) y se aprecian en otras fuentes: "le subyuga el amor a un sugestionador fementido, que le saca del hogar paterno, satisface sus caprichos y le abandona luego de haberla transformado en madre" (ESCUELA MODERNA, 1902, p. 64).

En la cita que sigue se vuelve a ver la asociación entre el matrimonio y el sometimiento femenino: "la oprime y le impone silencio, o la trata como niño mimado... a gusto del antojadizo señor" (ESCUELA MODERNA, 1901b, p. 17), así como en otros trabajos: Chaughi (1902), Ferrer i Guàrdia (1912), en Rino (1903) y en un cuento editado por la Escuela Moderna, Tierra libre de Grave (1908), en el cual se indica que las mujeres casadas viajaban si sus maridos daban su permiso y siempre que fuera junto a ellos.

No obstante, una de las críticas más impactantes sobre el sometimiento femenino compara al matrimonio con la prostitución:

Nuestra profesión sufre la concurrencia de las mujeres legítimas. La principal diferencia entre estas profesiones consiste en que nuestras concurrentes trafican al por mayor y nosotras al menudeo. Nosotras 
vendemos nuestra mercancía a todo el mundo; ellas la suministran a un contratista vitalicio (...). En general, las aspirantes al matrimonio tienen en tan poca estimación su propio valor, que en lugar de hacerse pagar lisa y llanamente como nosotras, se ven obligadas a presentar un dote, es decir, una cantidad para darse de balde y con dinero encima. Su valor es, pues, negativo, menor que nada (ROBIN, 1908, párr. 3-5).

El siguiente apartado trata sobre los convencionalismos y la importancia que daban las publicaciones racionalistas al amor como base para contraer matrimonio.

\section{CONVENCIONALISMOS Y LA IMPORTANCIA DEL AMOR}

En otros textos se crítica que el matrimonio fuese planteado como un privilegio para las mujeres con posibilidades económicas y como un privilegio respecto a la alternativa de ser una mujer soltera o solterona, adjetivo despectivo que se utilizaba muy a menudo hacia la mujer que no conseguía la deseada unión del matrimonio. Esta terminación daba por supuesto que la soltería era un tipo de vida que la mujer no debía desear y, posiblemente, muchas se entregaban al matrimonio para huir de tales apreciaciones sociales, que a su vez podían ser potenciadas con ideas como las que mostramos a continuación, aunque no fueran su intención:

Les damos un concepto erróneo de la vida y dejamos que cuenten con el matrimonio para conseguir una existencia pasadera; pero el matrimonio va quedando como un privilegio para las que tienen dote, que es una especie de propina que la mujer da al hombre que le hace la merced de tomársela a sus padres para hacer de ella una "señora," y as que carecen de dote tienen muchas probabilidades de que no se presente quien las tome, y entonces quede en la lamentable condición de señorita solterona a cargo de los padres, hasta que, envejecidas, agotadas, acaban su existencia inútil en las prácticas de una devoción necia (SÉE, 1902, p. 98). 
Desde nuestro punto de vista, la cita anterior critica las dos opciones que se imponían a la mujer: el deseo de una vida llevadera en matrimonio o el padecimiento de la soltería. Aunque fuera establecida como una visión crítica, ideas como las anteriores tenían el riesgo de mantener estereotipos sobre la mujer que no contraía matrimonio, al describirle una vida asociada a la vejez, al agotamiento y a la pobreza. Lo que daba lugar a que se asociara al matrimonio con la juventud, la energía vital y la riqueza.

En otras citas se comparaba al hombre primitivo con el hombre de aquel momento, considerando que ambos mantenían la misma violencia y que ésta era utilizada para someter a la mujer. Al contemporáneo de la época también se le atribuía la astucia, la cual era utilizada para subyugar a la mujer de la misma manera que lo hacían los primeros hombres con el uso de la violencia. Así pues, vemos que la astucia no era empleada para fines honestos, como podía ser el de convertir a la mujer en una igual:

Si el hombre primitivo se apoderaba de su esposa por la violencia, nosotros lo hacemos por la astucia, manteniéndola en completa ignorancia del matrimonio y de la vida, y pidiéndole un consentimiento que, por sus condiciones especiales, resulta completamente falaz; si aquél consideraba su compañera como propiedad suya, en igual concepto la tenemos nosotros; si sobre ella tenía derecho de vida y muerte, nosotros también. Aterrorizamos a la joven por medio de convencionalismos forjados por nosotros en nuestro provecho, $\mathrm{y}$ hacemos otro tanto con la esposa valiéndonos de leyes sanguinarias. Queda, pues, en vigor el régimen de rapto y de violencia implantado por nuestros antepasados los monos (CHAUGHI, 1902, p. 27).

En la cita anterior, es probable que Chaughi (1902) se esté refiriendo a las personas en sentido genérico, porque se critica al acto de atribución de los convencionalismos forzados, al cual contribuía la sociedad en general. Otro documento que critica esta práctica de asignación social cara a la mujer es el de A. L. (1902) de Flor de Invernáculo.

De nuevo en la cita posterior, se critica a los convencionalismos, pero es 
posible que la forma de realizarlo diera como resultado la visibilidad y el mantenimiento de los mismos, ya que se utilizaban terminaciones como el de solterona, para la mujer no casada, y se consideraba la posibilidad de que envidiaran a las mujeres que vivían en matrimonio. Asimismo, se pintaba a la mujer casada como una mujer provista de fortuna, siendo ésta y, no el amor, el motivo que la llevaba a contraer matrimonio. Por tanto, parece como si no hubiera una buena imagen de la mujer que se casaba ni tampoco de la que no lo hacía. Por otro lado, es posible que al asociar a la mujer casada con el lujo se potenciara la necesidad de la vida en matrimonio, aunque toda la cita posterior se escribiese con intenciones críticas hacia la sociedad:

¿Aquella novia que va a casarse, deslumbradora de diamantes y envuelta en oleadas de encaje, que seca de envidia a tres muñecas solteronas que amarillean a su lado, por qué se casa? ¿Creéis que es para ser dichosa con el marido que ama y para disfrutar con él las delicias del hogar? iAh! os equivocáis: en lo que piensa es en que tendrá coche lujoso, palco en el teatro y brillantes soirées, dominando en ella la vanidad sobre el amor (ESCUELA MODERNA, 1902a, p. 71).

La importancia que daban las publicaciones racionalistas a la unión basada en el amor se ve en numerosas ocasiones. Una de ellas trata sobre el análisis de la sociedad del porvenir por parte de Enrique Lluria4:

La verdadera base de la familia futura será el amor, que en la especie humana es el medio natural de selección [...]. Cambiando la base económica la propiedad, por la base efectiva intelectualizada el amor, la transformación será maravillosa (LLURIA, 1905, pp. 5-6).

En otra de sus obras destacadas dentro de los temas sociológicos, Enrique Lluria vuelve a destacar la importancia del amor como base de la unión entre las

\footnotetext{
4 Discípulo de Ramón y Cajal. Este último realizó el prólogo de la obra de Enrique Lluria: Evolución super orgánica (la naturaleza y el problema social). Barcelona: Publicaciones de la Escuela Moderna, 1905.
} 
personas. Siendo considerado el tipo de vínculo predominante en las relaciones venideras:

Las familias, en el Porvenir, no correrán ese riesgo; su capital será la inteligencia, y ésta la podrán conservar y acrecentar de una a otra generación, porque entonces las uniones no se harán como se hacen hoy, muchas dependientes de la situación económica, sino que los individuos se unirán guiados por el amor, y como en el verdadero amor lleva inherente la idea de la reproducción, el sentimiento natural será el de mejorarla. En una palabra, la selección será más natural y legítima (LLURIA, 1906, p. 80-81).

En un cuento de aplicación escolar escrito por Urales (1906), Sembrando flores, que narra la historia de Floreal Ramos5, encontramos de nuevo la importancia de generar un vínculo amoroso basado en el amor. Además, en este trabajo, se añade la importancia de no obligar a nadie a vincularse con otra persona y de tener la posibilidad de acabar una relación cuando el amor se da por finalizado. Estas mismas ideas también aparecen en el trabajo de Naquet (1909).

Lorenzo (1909) también dedica un apartado a la importancia del sentimiento amoroso y sus aportaciones añaden que los celos y la rivalidad no forman parte de los asuntos del corazón.

Finalmente, en Bessède (1917) se recomienda que la unión conyugal tenga lugar después de que las personas se conozcan mínimamente y se tengan algo de aprecio.

\section{ESCÁNDALOS SOCIALES VINCULADOS A LA MUJER CASADA}

Las ideas que siguen demuestran que, en las publicaciones de la Escuela

\footnotetext{
5 Comenzado la misma con su nacimiento y sus primeros años en un Colegio Libre, que nos recuerda a las descripciones de la Escuela Moderna.
} 
Moderna, se trataban ciertos escándalos sociales sobre el matrimonio que nos siguen acompañando siglos más tarde. Estos están relacionados con los matrimonios mal avenidos de las familias más adineradas, las malas madres, el adulterio femenino y la mujer que no se consideraba apta para el matrimonio.

En la cita posterior encontramos un ejemplo de las situaciones negativas que pueden tener lugar en un matrimonio de una familia acomodada. Resulta una idea novedosa, pues se suelen asociar las desdichas matrimoniales con los hogares desafortunados económicamente. Así pues, encontramos el caso de una supuesta familia con recursos socioeconómicos y con dificultades de convivencia, así como con una esposa que busca el control de la descendencia femenina. Estas ideas vuelven a generar ideas negativas sobre el matrimonio y la mujer, haciendo ver al lector que, incluso en las mejores familias, los hogares que se construyen mediante el matrimonio pueden derivar en un hogar asfixiante para todos los miembros, siendo la principal causante de este clima la esposa:

iQué dramas se desarrollan en el interior de tantas y tantas familias acomodadas, que presentan al mundo un aspecto respetable!... La falta de benevolencia y la antipatía de los esposos se continúa en los hijos, y, sobre todo, de madre a hija se ejercita con una crueldad excesiva; porque al fin, el padre y los hijos pueden salir de la casa; pero la hija permanece siempre en ella, y hasta para salir no se separa de su madre, quien puede tiranizarla a su antojo (MAUR, 1903, p. 92).

En la cita anterior de Maur (1903) aparecen algunas ideas que no son las que se esperan para describir a una mujer casada y que es madre; por esta razón, las hemos añadido, porque dan otra imagen de esta figura, es decir, nos sorprenden hablando de la existencia de los dos tipos de maternidades y la que es peor considerada, incluso, se llega asociar con la clásica madrasta, en otras palabras, con una mujer que no comparte los vínculos biológicos con su descendencia. Esta cita es la continuación de la anterior y, en ella, vemos una vez más las ideas relacionadas con esposas que generan climas asfixiantes y maltratan a sus hijas: 
Hay madres adorables, bien sabido es y harto y tal vez con exceso se ha repetí-do; pero hay otras que son peores que la madrastra legendaria, y por toda excusa puede decirse de ellas que no saben lo que hacen. Envenenado su carácter, se vengan del marido sobre los hijos que se le parecen, y a veces agravan su maldad dando la preferencia al hijo en quien creen verse reproducidas. Hay hermano brutal que ayuda a su madre a mortificar a su hermana, y bajo sus malos tratamientos y su ironía continua, la pobre joven se hace tímida y torpe, a menos que no sepa librarse a tiempo (MAUR, 1903, p. 92).

Tal y como hemos indicado más arriba, otro de los temas que trata las publicaciones racionalistas es el del adulterio femenino, el cual, como era de esperar de la época, era tratado de manera diferente en función de quien lo llevara a cabo, siendo la mujer considerada de peor manera. Aparte de esta idea se sigue reflexionado sobre la sumisión femenina, la mujer como propiedad del hombre desde tiempos prehistóricos y sobre el interés que prima sobre el amor en lo que se refiere al enlace matrimonial:

\begin{abstract}
A la simple lectura del Código se ve claramente que los hombres han hecho las leyes: la manera con que los legisladores hablan de los derechos y de los deberes de cada uno de los esposos, el diferente modo con que consideran el adulterio del uno y de la otra (...). Así, por ejemplo, mientras el poder legal del marido es casi ilimitado, el de la esposa es nulo; ella le pertenece, (...) pudiendo decirse con toda verdad que la mujer del día, lo mismo que la de las edades prehistóricas, no es una persona sino una cosa apropiada. Para que el amor nazca y persista entre ese amo y esa sierva son necesarias circunstancias bien excepcionales; a falta de ellas, casi nunca hay amor, sólo hay cambio de dos deseos momentáneos, u otra cosa peor: brutalidad y sumisión (CHAUGHI, 1902, p. 27-28).
\end{abstract}

Por otra parte, en la obra de teatro de Floreal. Drama social en tres actos de Chardon (1906) se plantea una posible sociedad alternativa, en la cual el dinero carece de utilidad y el trabajo gana protagonismo, así como la felicidad basada en el esfuerzo. Dentro de este documento, vemos que uno de los personajes es un cura que incita a uno de los protagonistas a no casarse con una de las mujeres de la obra, por considerarla una oveja descarriada y, además, 
añade: "seductoras, porque adulan los apetitos del cuerpo, siempre groseros... (CHARDON, 1906, p. 67). Aunque esta obra teatral se base en una sociedad hipotética, se realizó siguiendo los patrones sociales del momento.

En el punto posterior reflexionaremos sobre algunas de las claves para salvaguardar a la mujer de la sumisión que la esperaba en la vida de casada. Para tal fin, incidiremos en el papel de la educación.

\section{EL PAPEL DE LA EDUCACIÓN PARA LA EMANCIPACIÓN DE LA MUJER CASADA DEL MOMENTO}

El fundador de la Escuela Moderna se caracterizaba por su confianza en la educación, para poner fin al sometimiento que padece la sociedad debido al sistema sociopolítico establecido en cada momento. Incluso, después de la clausura de su escuela, Ferrer i Guàrdia siguió viendo a la educación como la clave para mejorar la sociedad, pero siempre que ésta fuera liberadora para el hombre y la mujer (Ferrer i Guàrdia, 1908).

Se consideraba también que una de las principales claves para mejorar la situación de la sociedad en general y de la mujer en particular, ya fuera casada o no, era solicitar la igualdad de la mujer respecto al hombre en todos los ámbitos de la vida, siendo uno de los destacados el matrimonio (LA ESCUELA MODERNA, 1901b; LETOURNEAU, 1901). La cita que sigue así lo demuestra:

\footnotetext{
En nuestra organización social, tal cual es con sus imperfecciones y sus vicios, es ya posible mejorar notablemente la suerte de las mujeres; pero la evolución, más o menos rápida, que se prepara no puede reducirse solamente a uno de los sexos; para que la condición de las mujeres sea digna y justa es preciso que la de los hombres se modifique en el mismo sentido; es necesario que una reforma gradual pero profunda transforme todas las instituciones: el matrimonio, la familia, el régimen de la propiedad y el del trabajo (LETOURNEAU, 1901, p. 27).
} 
También se consideraba que era fundamental que las escuelas apostaran por una reforma en lo que se refiere a la educación femenina, pues su enseñanza se limitaba a que entregaran su vida al matrimonio. Asimismo, la educación debería orientar a la mujer que no se casaba, para que pudiera ver que la soltería también era un camino posible, e inculcar en la cultura del esfuerzo con el objetivo de crear mujeres independientes:

Sí, vengan esas ansiadas reformas, especialmente en materia de educación femenina; porque la verdad es que hay mucho que hacer entre nosotros para poner la educación de la mujer al nivel de lo que los tiempos actuales exigen. La creación de colegios superiores de señoritas no ha modificado la costumbre vieja. El nuevo colegio es aún el antiguo pensionado, que, como aquél, da una educación de lujo para mujeres destinadas a la vida fácil en un sitio agradable. ¿Qué se enseña a nuestras jóvenes que pueda servirles para orientar su vida inteligentemente si no encuentran marido? ¿Se les enseña a ejercer su voluntad? ¿Se les patentiza la alegría del esfuerzo? (SÉE, 1902, p. 98).

La educación femenina no solo debería encontrarse en la escuela, pues la mujer también debería educarse a sí misma, para aprender y ser consciente de su situación. Una vez que fuera consciente debería poner sus esfuerzos en negarse a someterse a una vida recluida al hogar, acompañada de los lujos entendidos como tal por la sociedad del momento. Siendo el mayor lujo de todos, al que debería aspirar, la libertad, y la cual no habría ninguna duda que alcanzaría:

Es menester que eso acabe. Es preciso que la mujer tenga conciencia de sí misma, que se avergüence de su estado actual y que se niegue a ser una muñeca lujosa o una doméstica y sobre todo una cosa apropiada. Urge que aprenda que no hay dignidad posible ni menos moralidad para un ser consciente más que en la libertad, en la plena posesión de sí mismo que quiera ser libre, y lo será (CHAUGHI, 1902, p. 29).

Posteriormente vemos, de una manera más detallada, la realidad basada en la posesión de objetos de la que debían salir las mujeres, ya que las alejaba de disfrutar de su propio esfuerzo y las llevaba hacia un camino de inmoralidad: 
Después de siglos y siglos de esclavitud, ha conservado costumbres, pensamientos y gustos de esclava. Observadla: en la más honesta encontraréis huellas de venalidad, aunque sólo sea respecto de su marido. Al ofrecimiento de un vestido nuevo, de un regalo cualquiera, se manifiesta más cariñosa, lo que es vergonzoso. Como todos los esclavos, aplaude el éxito, y prefiere la medianía que llega a brillar al mérito positivo que permanece obscurecido; siente necesidad insana de aparentar, de atraer las miradas, de dominar, de humillar. Como los salvajes, gusta de clorados, cristalería y relumbrones inútiles; pasa horas enteras ante los escaparates de joyería admirando cosas feas pero brillantes; se cubre de collares, brazaletes, sortijas, pendientes, cintas y perifollos que no tienen razón de ser, pero que cuestan mucho y dificultan la lucha por la vida (CHAUGHI, 1902, p. 29).

En algunas hojas del Boletín de la Escuela Moderna se establecía que la libertad de la mujer supondría el fin de las guerras (CHAUGHI, 1902). Además, en ésta y otras publicaciones se consideraba que, si se retiraba de la ignorancia a la mujer mediante la educación, se produciría el progreso (ANTICH, 1915; FERRER I GUÀRDIA, 1912; LA ESCUELA MODERNA, 1901b; 1902c y LETOURNEAU, 1901) y se evolucionaría a un tipo de sociedad pacífica y, por ende, más evolucionada y superior:

La mujer libre es una revolución en el mundo cuyas consecuencias son incalculables: es el fin de las religiones, que sólo por ella subsisten, y por ella dominan aún al niño y al hombre; es también el fin de la guerra, que detestan cordialmente las esposas y las madres, porque aquélla es asesina de maridos y de hijos; la adaptación de la mujer a las tareas humildes dé la servidumbre ha producido algo bueno, le ha hecho perder los hábitos de la brutalidad, el gusto del asesinato. La mujer instruida, apoyada en la vida social, es un medio de pacificación y desarme mucho más eficaz que las mentidas palabras de los déspotas; es su completa dignificación, a la par que el fin del reino de la violencia y del sacrificio de los débiles por los fuertes; es el advenimiento de la verdad, de la belleza y de la justicia. La mujer libre es una humanidad nueva que surge y vive en la verdadera acepción de la idea de vida (CHAUGHI, 1902, p. 29).

Ferrer i Guàrdia mantiene las mismas ideas sobre la educación femenina:

"La humanidad mejoraría con más aceleración, seguiría con paso más firme y 
constante el movimiento ascensor del progreso y centuplicaría su bienestar, poniendo a contribución del fuerte impulso sentimiento de la mujer las ideas que conquista la ciencia” (FERRER I GUÀRDIA, 1912, p. 33).

En definitiva, a lo largo de este artículo, vemos que, aunque se asocie a la mujer con la vanidad, con las pretensiones materiales, etc., también hay una creencia firme en su valía y en su importancia para hacer avanzar a la sociedad, al considerarse que no solía tener interés por la brutalidad y la violencia. No obstante, hemos de señalar, partiendo de una de las citas anteriores, otra idea, ya que se indica que la mujer es la encargada de mantener la religión y, para los racionalistas, la religión es un cuento para nublar el juicio a los niños (FERRER I GUÀRDIA, 1912; PI Y MARAGALL, 1907, etc.) y se ha de superar la misma para llegar al estado racional (ELSLANDER, 1908a). Por tanto, se asocia a la mujer con ideas sin bases científicas y se considera que intervienen de manera negativa en el pensamiento lógico de la sociedad futura, pues los críos, de los que estaban a cargo, son los que representarían las generaciones posteriores. Aunque estas atribuciones forman parte de otro análisis diferente al nuestro. Sin embargo, hemos considerado oportuno hacer este apunte, para reflejar la sensación que nos queda al analizar las publicaciones de la editorial de la Escuela Moderna: por un lado, hay una gran confianza en la mujer del futuro, pero por otro aparecen varias críticas hacia la mujer de aquel momento, las cuales consideramos que se pueden interpretar como un intento de sacarlas de su sometimiento.

Finalmente, queremos añadir que también se consideraba que la educación tenía que ser complementaría a la función tradicional y biológica, a la se ha delegado a las mujeres durante siglos, y que es la conocida maternidad:

Mucho mejor que en billetes de banco o en títulos de rentas existiría el dote si la educación de las mujeres fuera diferente; como que estaría constituida por lo que los alemanes llaman las virtudes económicas o caseras de la mujer, y también por una mentalidad superior; lo que permitiría a la mujer ayudar a su marido, ser su colaboradora y adjunta, sin perjudicar con ello a su cualidad de madre; lo que le haría ser menos pasiva, más resuelta, y con lo que indudablemente ganaría en concepto de generadora y educadora: de ese modo tendría una maternidad doble, 
la material y la moral (SÉE, 1902, p. 99).

En la publicación de Elslander (1908), también se mantenía que las tareas académicas de las niñas tenían que estar dirigidas a que la futura mujer ocupase sus funciones de madre y esposa.

Algo que otros renovadores de la pedagogía, como algunos institucionistas promovían, pues luchaban por la educación de la mujer, pero ésta no debía distraerla de sus labores maternales (BALLARÍN, 1989).

\section{DISCUSIÓN Y CONSIDERACIONES FINALES}

Desde el análisis recién presentado, identificamos con relación al primer objetivo (analizar la realidad de la mujer casada de principios del siglo XX desde las publicaciones racionalistas de la Escuela Moderna) que las mujeres estaban presionadas a llevar una vida de casada, debido a que la soltería no se asociaba a un tipo de vida deseada. Esta circunstancia se vinculaba al agotamiento, a la envidia y a la vejez y, a su vez, se presentaba como un suceso no deseado. Estos convencionalismos se criticaban dentro de las publicaciones racionalistas analizadas, aunque posiblemente la forma de hacerlo no fuera la más apropiada al realizar las asociaciones recién indicadas; las cuales podían contribuir a mantenerlos.

También identificamos, en las hojas analizadas, una sensación de disconformidad con la mujer casada y con la que no lo estaba, porque se buscaba que la primera saliera de su sometimiento y que la segunda no vivera amargada, al no saber sacarle provecho a otra forma de vida que no fuera la de permanecer vinculada a un hombre en matrimonio. Ahora bien, a pesar de estas afirmaciones, se mostraba confianza hacia la mujer del futuro, haciendo alusión a su posible conquista de la libertad y al poner en entredicho a determinados escándalos sociales que, en el caso de llevarlos a cabo el hombre, no le afectarían a su 
reputación.

En lo que respecta al segundo objetivo (analizar el valor que tenía la educación para el desarrollo de la mujer casada) vemos que se tenía muy claro que todas las mujeres (casada, soltera y la del futuro) deberían encontrar su aliada en la educación, pues las dirigiría hacia la búsqueda de su autonomía, a disfrutar de su vida independientemente de su estado civil y a luchar por su libertad y las causas justas.

Con todas estas ideas y las que aparecen en el apartado anterior de resultados vemos que los racionalistas, de principios de siglo XX, tenían una idea pesimista de matrimonio debido al sometimiento femenino y a la falta de conciencia de esta situación por parte de la sociedad en general.

Por otro lado, al igual que Godoy (2011), encontramos que, para los anarquistas, el matrimonio debía tener como base el amor y alejarse del interés en la fortuna de tipo económica.

Por último, hemos de añadir que no podemos obviar que, en el Boletín de la Escuela Moderna, hay publicaciones que dan protagonismo a la mujer científica, a la mujer que salvaba a los pueblos de tiranos, etc. (ESCUELA MODERNA, 1902b). Tampoco podemos olvidar otros trabajos previos en los que se refleja a una mujer trabajadora que salía de su hogar para trabajar en fábricas durante jornadas laborales muy extensas, alejadas de sus hijos, con el único fin de llevarles sustento (SCOTT, 1993). Incluso, se ha identificado que otras mujeres vivían y trabajaban en el campo y desempeñaban funciones muy similares a las de sus maridos (BALLARÍN, 1989). Estas ideas y muchas otras son fundamentales para representar el valioso papel de la mujer, a lo largo de la historia, más allá de su estado civil y, por eso, consideramos que pueden ser temas que se pueden examinar desde la visión de los racionalistas u otros proyectos pedagógicos. 


\section{REFERENCIAS}

A. L. Flor de Invernáculo. Boletín de la Escuela Moderna, v. 7, 86-87, may. 1902, año I.

ANTICH, José. La Pedagogía de Francisco Ferrer. Barcelona: Conferencia editada por las Publicaciones de la Escuela Moderna, 1915.

ARCHER, William. Vida, proceso y muerte de Francisco Ferrer i

Guàrdia. Barcelona: Tusquets Editores, 2010.

AUBERT, Adriana; SILES, Gregori. Centenario de Ferrer i Guàrdia: Historia y Sociología de la posibilidad. Revista de la Asociación de Sociología de la Educación, v. 2, n. 2, p. 13-31, may. 2009. Disponible en:

https://ojs.uv.es/index.php/RASE/article/view/8657/8200. Acceso: 11 feb. 2021.

AVILÉS, Juan. Francisco Ferrer i Guàrdia: pedagogo, anarquista y mártir. Madrid: Ediciones de Historia, 2006.

BALLARÍN, Pilar. La educación de la mujer española en el siglo XIX. Revista Historia de la Educación: Revista Interuniversitaria, v. 8, p. 245-260, ene./dic. 1989. Disponible en: https://revistas.usal.es/index.php/o2120267/article/view/6837. Acceso: 11 feb. 2021.

BENOT, Eduardo. Los grandes pensadores: temas varios. Barcelona: Publicaciones de la Escuela Moderna, 1916.

BERGASA, Francisco. ¿Quién mato a Ferrer i Guàrdia? Madrid: Aguilar, 1990.

BESSÈDE, G.M. Lo que todos deberían saber (La iniciación sexual). Barcelona: Casa Editorial Publicaciones de La Escuela Moderna, 1917.

CAPPELLETTI, Ángel. Francisco Ferrer Guàrdia y la Pedagogía

Libertaria. Madrid: La Malatesta Editorial, 2010.

CHARDON, Jean. Pierre. Floreal. Drama social en tres actos. Barcelona: Publicaciones de la Escuela Moderna, 1906.

CHAUGHI, René. La mujer esclava. Boletín de la Escuela Moderna, v. 3, p. 27-29, dic. 1902, año II.

CIEZA, José. Antonio. Mentalidad y educación en España durante el primer tercio del siglo XX. Historia de la Educación: Revista 
Interuniversitaria, v. 5, p. 299-316, ene./dic. 1986. Disponible en: https://revistas.usal.es/index.php/0212-0267/article/view/6713. Acceso: 11 feb. 2021.

DELGADO, Buenaventura. L'Escola Moderna de Ferrer i Guàrdia. Barcelona: Eumo, 1982.

ELSLANDER, Jean-François. La Escuela Nueva. Bosquejo de una educación basada sobre las leyes de la evolución humana. Barcelona: Publicaciones de la Escuela Moderna, 1908.

ELSLANDER, Jean-François. L'éducation naturelle. L'École Rénovée, v. 15, n. 1, p. 19, abr. 1908a.

ESCUELA MODERNA. Escuela Moderna. Grupos de Estudios Pedagógicos. Programa de diciembre de 1901. Boletín de la Escuela Moderna, v. 2, p. 2021, nov. 1901, año I.

ESCUELA MODERNA. Primera clase preparatoria. Boletín de la Escuela Moderna, v. 1, p. 10-13, oct. 1901a, año I.

ESCUELA MODERNA. Necesidad de la enseñanza mixta. Boletín de la Escuela Moderna, v. 2, p. 17-20, nov. 1901b, año I.

ESCUELA MODERNA. Las conferencias de la Escuela Moderna. Boletín de la Escuela Moderna, v. 5, p. 63-64, mar.1902, año I.

ESCUELA MODERNA. Pensando en vosotros. Boletín de la Escuela Moderna, v. 6, p. 71-72, abr. 1902a, año I.

ESCUELA MODERNA. Las conferencias de la Escuela Moderna. Boletín de la Escuela Moderna, v. 4, p. 51-52, feb. 1902b, año I.

ESCUELA MODERNA. Segundo año escolar 1902-1903. Boletín de la Escuela Moderna, v. 1, p. 1, oct. 1902c, año II.

FERNÁNDEZ, Laura. Amor y sexualidad en las publicaciones anarquistas (Argentina, 1890-1930). Entrepasados. Revista de Historia, v. 32, p. 59-75, jun./dic. 2007. Disponible en: https://ahira.com.ar/ejemplares/entrepasadosno-32/. Acceso: 11 feb. 2021.

FERRER I GUÀRDIA, Francisco. La Rénovation de l'école. L'École Rénovée, v. 15, n. 1, p. 9, abr., 1908.

FERRER I GUÀRDIA, Francisco. La Escuela Moderna. Póstuma explicación y a alcance de la enseñanza racionalista. Barcelona: 
Tusquets, 1912.

GARCÍA-YESTE, Carme; REDONDO-SAMA, Gisela; PADRÓS, Maria; MELGAR, Patricia. The Modern School of Francisco Ferrer i Guàrdia (18591909), an international and current figure. Teachers College Record, v. 118, n. 4, abr. 2016.

GODOY, Eduardo. Lucha temperante y 'amor libre'. entre lo prometeico y lo dionisíaco: el discurso moral de los anarquistas chilenos al despuntar el siglo XX. Cuadernos de Historia, v. 34, jun. 2011. Disponible en: http://dx.doi.org/10.4067/So719-12432011000100006. Acceso: 11 feb. 2021.

GRAVE, Jean. Tierra libre. Fantasía comunista. Barcelona: Publicaciones de la Escuela Moderna, 1908

JACQUINET, Clemencia. Observaciones generales, sobre el primer mes de clase. Boletín de la Escuela Moderna, v. 1, p. 8-10, oct. 1901, año I.

LÁZARO, Pedro. Francisco Ferrer Guàrdia y la Escuela Moderna de Barcelona. Padres y Maestros, v. 366, p. 83-88, jun. 2016. Disponible en: https://revistas.comillas.edu/index.php/padresymaestros/article/view/6805. Acceso: 11 feb. 2021.

LETOURNEAU, Charles. Solidaridad de los sexos. Boletín de la Escuela Moderna, v. 2, p. 27, nov. 1901, año I.

LORENZO, Anselmo. El banquete de la vida. Concordancia entre la naturaleza, el hombre y la sociedad. Barcelona: Publicaciones de la Escuela Moderna, 1909.

LLURIA, Enrique. Evolución super orgánica (la naturaleza y el problema social). Barcelona: Publicaciones de la Escuela Moderna, 1905.

LLURIA, Enrique. Humanidad del porvenir. Barcelona: Publicaciones de la Escuela Moderna, 1906.

MARÍN, Dolors. La Semana Trágica: Barcelona en llamas, la revuelta popular y la Escuela Moderna. Madrid: La Esfera de los Libros, 2009.

MAUR, Alicia. La discordia en la familia. Boletín de la Escuela Moderna, v. 8, p. 91-92, may. 1903, año II.

MUÑOZ, Jaime. Novelar contra la miseria. Corrupción y literatura durante la Restauración Borbónica (1875-1923). Hispania Nova, v. 16, p. 558-589, dic. 2018. 
MURO, Nora. La enseñanza en la Escuela Moderna de Francisco

Ferrer i Guàrdia. Burgos: Gran Vía, 2009.

NADAL-MASEGOSA, Antonio. La mujer como autora en el Boletín de la Escuela Moderna en su primera época (1901-1903). En: INTERNATIONAL

CONFERENCE ON GENDER AND COMMUNICATION, 5, Sevilla, 2018. Disponible en: https://riuma.uma.es/xmlui/handle/10630/15643. Acceso: 11 feb. 2021.

NAQUET, Alfred. Hacia la Unión Libre. Barcelona: Publicaciones de la Escuela Moderna, 1909.

NASH, Mary. Mujer, familia y trabajo en España (1875-1936).

Barcelona: Anthropos, Editorial del Hombre, 1983.

NASH, Mary. Maternidad, maternología y reforma eugénica en España, 19001939. En: G. DUBY y M. PERROT (dir.), Historia de las mujeres, v. 5, Madrid, Taurus, 1993, p. 687-708.

ONTAÑÓN, Elvira. Un estudio sobre la Institución Libre de Ensenanza y la mujer. Valencia: Editorial UPV, 2003.

PALOMERO, Pablo. Cultura y educación en el anarquismo, España 1868-1939. Revista Interuniversitaria de Formación del Profesorado, v. 33, p. 183193, sept./dic. 1998.

PI Y MARAGALL, Francisco. La educación. Revista Pedagógica Ilustrada, v. 6, p. 4, ago. 1907.

R. El autoritarismo. Boletín de la Escuela Moderna, v. 7, p. 82-83, abr. 1903, Año II.

RINO, Juana. La servidumbre de la mujer. Boletín de la Escuela Moderna, v. 7, p. 79-80, abr. 1903, año II.

ROBIN, Paul. (1908). La mujer pública. Disponible en: http://www.filosofia.org/aut/o01/1908paul.htm. Acceso: 6 feb. 2020.

SAUERWEIN, Carlos. Historia de la tierra. Barcelona: Publicaciones de la Escuela Moderna, 1925.

SCANLON, Geraldine. La mujer y la instrucción pública: de la Ley Moyano a la II República. Revista Historia de la Educación: Revista Interuniversitaria, v. 6, p. 192-207, ene./dic. 1986. Disponible en: https://redined.mecd.gob.es/xmlui/handle/11162/22023. Acceso: 11 feb. 2021. 
SCOTT, Joan. La mujer trabajadora en el siglo XIX. En D. GEORGES Y M. PERROT (coord.), Historia de las Mujeres, tomo 8, el siglo XIX. Madrid: Tauros, 1993, p. 405-435.

SÉE, Ida. Cambios necesarios. Boletín de la Escuela Moderna, v. 8, p. 9899, jun. 1902, año I.

SERRALLONGA I URQUIDI, JOAN. (1991). Motines y revolución España, 1917. Ayer, v. 4, p. 169-191, oct./dic. 1991.

SOLÀ, Pere. Las coordenadas morales y filosófico-educativas de Ferrer.

Educació i Historia: Revista d'Història de l'Educació, v. 16, p. 43-78, jul./dic. 2010. Disponible en:

https://www.raco.cat/index.php/EducacioHistoria/article/view/224535.

Acceso: 11 feb 2021.

SOLÀ, Pere. Ferrer Guardia pedagogo y hombre de acción. La mirada apasionada de Alban Rosell sobre el fundador de la Escuela Moderna. Barcelona: Clavell Cultura, 2011.

TORREBADELLA, Xavier. Francisco Ferrer i Guàrdia, postmoderno avanzado y precursor de la Educación Física Crítica. Análisis y reflexión para un giro didáctico. Educar, v. 52, n. 1, p. 169-191, ene./jun. 2016. Disponible en: https://www.raco.cat/index.php/Educar/article/view/v52-n1-torrebadella. Acceso: 11 feb. 2021.

URALES, Federico. Sembrando flores. Barcelona: Publicaciones de la Escuela Moderna, 1906.

VELÁZQUEZ, Pascual. La Escuela Moderna: una editorial y sus libros de texto (1901-1920). Tesis doctoral (Doctorado en Educación)-Programa de Doctorado, Universidad de Murcia. Murcia, 2008.

VELÁZQUEZ, Pascual; VIÑAO, Antonio. Un programa de Educación Popular: El legado de Ferrer Guardia y la Editorial Publicaciones de la Escuela Moderna (1901-1936). Educació i Història: Revista d'Història de l'Educació, v. 16, p. 79-104, jul./dic. 2010. Disponible en:

https://www.raco.cat/index.php/EducacioHistoria/article/view/64208.

Acceso: 11 feb. 2021.

VIÑES, Cristina. La Renovación Pedagógica del siglo XIX y las colonias escolares de vacaciones. Revista de Historia Contemporánea, v. 2, p. 94124, 1983. Disponible en: https://idus.us.es/handle/11441/51048. Acceso: 11 feb. 2021. 
ESTEFANÍA FERNÁNDEZ-ANTÓN es doctora en Educación y Sociedad por la Universidad de Barcelona. Su tesis doctoral, financiada por el Ministerio de Educación y Cultura y Deporte, se desarrolló con el objetivo de analizar proyectos renovadores y transformadores de la Pedagogía, entre los cuales se encuentra la Escuela Moderna. Actualmente es profesora lectora de la Universidad Internacional de la Rioja. Su trayectoria profesional también comprende a la participación en proyectos de investigación nacionales y europeos sobre el impacto social de las Ciencias Sociales y la vulneración de los derechos de las mujeres.

E-mail: Estefania1fernandez@outlook.es

(7) http://orcid.org/0000-0002-4184-5400

Recebido em: 11 de fevereiro de 2020

Aprovado em: 15 de junho de 2020

Editora responsável: Tatiane de Freitas Ermel 